\title{
PHENOTYPE ANALYSIS OF TUMOUR-INFILTRATING LYMPHOCYTES AND LYMPHOCYTES IN PERIPHERAL BLOOD IN PATIENTS WITH RENAL CARCINOMA
}

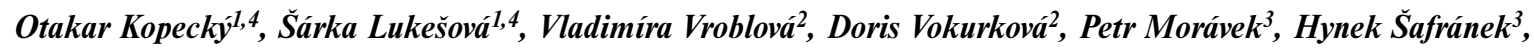 \\ Dagmar Hlávková ${ }^{2}$, Petr Souček ${ }^{2}$
}

Charles University in Prague, Faculty of Medicine in Hradec Králové and University Hospital Hradec Králové, Czech Republic: $2^{\text {nd }}$ Department of Internal Medicine, Division of Haematology ${ }^{1}$, Department of Clinical Immunology and Allergology ${ }^{2}$, Department of Urology ${ }^{3}$; Oncological Department of District Hospital, Náchod, Czech Republic ${ }^{4}$

Summary: Introduction: When checking tumour growth, a number of observations indicate that the immune system plays a significant role in patients with renal cell carcinoma (RCC). Infiltration by lymphocytes (tumour infiltrating lymphocytes, TILs) is more prevalent in RCC than any other tumours. T lymphocytes are the dominant population of TIL cells. Views concerning the role of T lymphocytic subpopulations, B lymphocytes and NK cells in an anti-tumour response are not established. Aim: The aim is to determine the phenotype and activation of T and B lymphocytic subpopulations and NK cells and to compare their representation in tumour stroma and peripheral blood lymphocytes (PBL) in patients with RCC. Material and methods: Samples of peripheral blood taken from the cubital and renal veins and tumour stroma cells were obtained from 44 patients in the course of their surgeries carried out due to primary RCC. TILs were isolated from mechanically disintegrated tumour tissue. Immunophenotype multiparametric analysis of PBL and TILs was carried out. Their surface and activation characteristics were determined by means of flow cytometer. Results: $\mathrm{CD}^{+} \mathrm{T}$ lymphocytes $(69.7 \%)$ were the main population of TILs. The number of $\mathrm{CD}^{+} / \mathrm{CD}^{+} \mathrm{T}$ lymphocytes was significantly higher in TILs, $42.6 \%(\mathrm{p}<0.01)$, while $\mathrm{CD} 4^{+} \mathrm{T}$ lymphocytes were the majority population in peripheral blood, $41.35 \%(\mathrm{p}<0.001)$. The representation of $\mathrm{CD}^{+} / 69^{+} \mathrm{T}$ lymphocytes was significantly higher in TILs, $32.9 \%$, compared to PBL (p<0.001). On the contrary, the numbers of $\mathrm{CD}^{+} / \mathrm{CD} 25^{+}, \mathrm{CD}^{+} / 57^{+}$and $\mathrm{CD} 4^{+} / \mathrm{RA}^{+}$(naive $\mathrm{CD} 4^{+} \mathrm{T}$ lymphocytes) were higher in $\mathrm{PBL}$ $(\mathrm{p}<0.001)$. The differences in representation of $\left(\mathrm{CD}^{-} / 16^{+} 56^{+}\right) \mathrm{NK}$ cells and $\mathrm{CD}^{+} / \mathrm{DR}^{+} \mathrm{T}$ cells in TILs and PBL were not significant. Conclusion: The above-mentioned results prove that the characteristics and intensity of anti-tumour responses are different in compared compartments (tumour/PBL). $\mathrm{CD}^{+} / \mathrm{CD}^{+} \mathrm{T}$ lymphocytes are the dominant lymphocytic population of TILs. The knowledge of the phenotype and functions of effector cells, which are responsible for anti-tumour response, are the basic precondition for understanding the anti-tumour immune response and the cause of its failure.

Key words: Tumour-infiltrating lymphocytes; $C D 4^{+}$; $C D 8^{+}$; Flow cytometry, Renal cell carcinoma

\section{Introduction}

Tumour diseases are one of the three most common causes of human death. Cytotoxic T lymphocytes and NK cells are responsible for the anti-tumour response. The cytotoxic activity of $\mathrm{T}$ lymphocytes may be realized through the exocytic pathway, during which perforins and granzymes are released, whose activity initiates the apoptosis process in target (tumour) cells (5). The second mechanism which leads to the initiation of tumour cell death is the pathway which includes pro-apoptotic activity of an Apo/Fas molecule and also the pathway mediated through TNF $\alpha$ (11). There is a great similarity between $\mathrm{CD} 8^{+}$cytotoxic $\mathrm{T}$ lymphocytes and NK cells in effector mechanisms of cyto- toxicity. There are a number of studies concerning RCC which analyse tumour-infiltrating cells and their contribution to the anti-tumour response. However, no unified opinion exists concerning the representation and role of $\mathrm{T}$ lymphocytic subpopulations, B lymphocytes and NK cells $(4,8,20,23)$.

\section{Aim}

The aim is to determine, by means of multiparametric analysis using flow cytometer, the phenotype and activation of cytotoxic cells and compare their representation in TILs and in blood taken from the renal and cubital veins. 


\section{Group of patients}

From April 2005 to February 2006, RCCs were removed by means of surgery in 44 patients. The group of patients consisted of 15 women and 29 men aged 31-82, with an average age of 65.9. In 42 patients, radical nephrectomy was carried out and in two patients partial resection of the kidney was performed. The bilateral findings of renal tumour was present in one patient, in whom a unilateral nephrectomy and tumour encapsulation were performed on the second affected kidney.

According to histological findings, $86 \%$ of the cases (36 patients) had primary clear cell carcinoma, $9 \%$ of the cases ( 4 patients) had papillary carcinoma, and in $5 \%$ of the cases ( 2 patients) chromophobe carcinoma was discovered. In one patient sarcomatoid carcinoma was caused by the transformation of chromophobe carcinoma; in another patient, non-classified RCC was diagnosed probably based on Henle's loop origin.

In order to determine the degree of disease progression, we used TNM classification. Twenty-two patients (50\%) with renal carcinoma were classified as primary tumour T1, twelve patients $(27 \%) \mathrm{T} 2$, nine patients $(20.5 \%) \mathrm{T} 3$ and one patient $(2.5 \%) \mathrm{T} 4$. The disease classification of stages complies with numeric indexes of the primary tumour $(\mathrm{T}-$ tumour). Only two patients who were classified $\mathrm{T} 1$ and one patient with T3 classification were ranked into stage IV due to the presence of metastases. $\mathrm{N}$ (noduli) in the TNM classification in two patients had the value of N1 due to metastases of regional lymphnodes. The other patients had negative findings in the nodes. $M$ (metastases) in TNM classification informs us about the presence of metastases. Three patients ( $7 \%$ ) were classified M1 due to distant metastases. In $93 \%$ of the patients no distant metastases were diagnosed and they were classified M0. On the day of operation, samples of tumour tissue and blood from cubital and renal veins were taken from each patient.

\section{Methods}

Heparinized test tubes were used in the collection of blood from cubital and renal veins. Tumour tissue was sampled in a physiological saline with heparin solution $(25$ $\mathrm{j} / \mathrm{ml}$ ) and mechanically disintegrated and homogenized into individual cellular elements by means of scissors, pincers and homogenizer. These cellular elements were filtrated, twice washed with physiological saline (Infusion Natrii Chlorati Isotonica, the IMUNA Company), and diluted to an approximate concentration of $5 \times 10^{5}$ cells. The samples were processed up to 12 hours after their sampling.

Each time $25 \mu \mathrm{l}$ of cellular suspension and heparinized blood were incubated for 20 minutes with $10 \mu \mathrm{l}$ of diluted conjungated monoclonal antibodies (the Immunotech Company and the Beckman Coulter Company) in the following combinations: CD45-FITC/CD14-PE, CD3-FITC/ CD 16 ${ }^{+}$56-PE/CD19-PC5, RO-FITC/RA-PE/CD4-PC,
CD8-FITC/DR-PE/CD3-PC5, CD69-FITC/CD25-PE/ CD3-PC5, CD 57-FITC/TcR $\alpha \beta-P E / C D 8-P C 5$, CD 34FITC/CD105-PE. Monoclonal cells in CD44-FITC/ CD105-PE combination were used for the evidence of cellular endotheliums.

After lysing erythrocytes with lysing solution $(0.5 \mathrm{ml}$ OptiLyse C, the Beckman Coulter Company), we added physiological saline with $5 \%$ natrium azide $(1.5 \mathrm{ml} \mathrm{Na}-$ triumazid-MERCK ${ }^{+}$Infusio Natrii Chlorati Isotonica, the IMUNA Company). The measurement was carried out by means of Coulter ${ }^{\circledR}$ Epics ${ }^{\circledR}$ XL flow cytometer (the Coulter Company, Fullerton, USA) equipped with an air-cooled argon laser emitting light with a wave length of $488 \mathrm{~nm}$. This cytometer is equipped with four filters which absorb light beams of various wave lengths. This is why we were able to use three different fluorescent stains in one sample. The evaluation of measured samples was carried out by means of CPX software analysing programme.

The Sigmastat version 2.0 programme was used for statistical evaluation. The statistics were processed by standard methods for statistical comparison of several groups. The normality value test was, in the evaluated cases, unsuccessful, therefore the "One Way Anova on Ranks" test was carried out to determine the level of statistical significance. The median was the indicator of value position.

\section{Results}

The mean purity of the lymphocyte suspensions isolated from the tumour was $86.5 \%$ and did not cause any problems during measuring and comparing the findings in the samples of venous blood and tumoral cellular suspension. The results of measurements are shown in was Tab. 1. The number of cells carrying $\mathrm{CD}^{+} / 69^{+}, \mathrm{CD}^{+}$and $\mathrm{CD}^{+} /$ $8^{+}$phenotype were significantly higher in TILs compared to PBL (with lymphocytes in blood from renal and cubital veins). On the contrary, the number of cells with $\mathrm{CD} 4^{+}, \mathrm{CD}$ $19^{+}, \mathrm{CD}^{-} / 8^{+}, \mathrm{CD}^{+} / 16^{+} / 56^{+}, \mathrm{CD}^{+} / 25^{+}, \mathrm{CD}^{+} 7^{+}, \mathrm{CD}^{+} /$ $57^{+}, \mathrm{CD}^{+} / \mathrm{RA}^{+}$phenotype was significantly higher in $\mathrm{PBL}$ compared to TILs. CD ${ }^{+} \mathrm{T}$ lymphocytes were the dominant lymphocytic population in tumour tissue. On the contrary, $\mathrm{CD}^{+} \mathrm{T}$ lymphocytes were the majority population in peripheral and renal venous blood. The representation of (CD $\left.3^{-} / 16^{+} / 56^{+}\right) \mathrm{NK}$ cells and $\mathrm{CD}^{+} / \mathrm{DR}^{+}, \mathrm{CD}^{+} / \mathrm{DR}^{+}, \mathrm{CD} 25^{+}$ and $\mathrm{CD}^{+} / \mathrm{RO}^{+} \mathrm{T}$ lymphocytes showed no statistically significant differences (Fig. 1).

\section{Discussion}

Clinical monitoring of both spontaneous regressions of RCC primary and secondary foci and therapeutic responses in 15-20\% of patients after the administration of IL-2 shows an effective anti-tumour response. Tumour-infiltrating lymphocytes are responsible for the anti-tumour response. This is a heterogeneous population of cytotoxic cells that carry predominantly $\mathrm{CD}^{+} / \mathrm{CD}^{+}$and $\mathrm{CD}^{-} /$ 

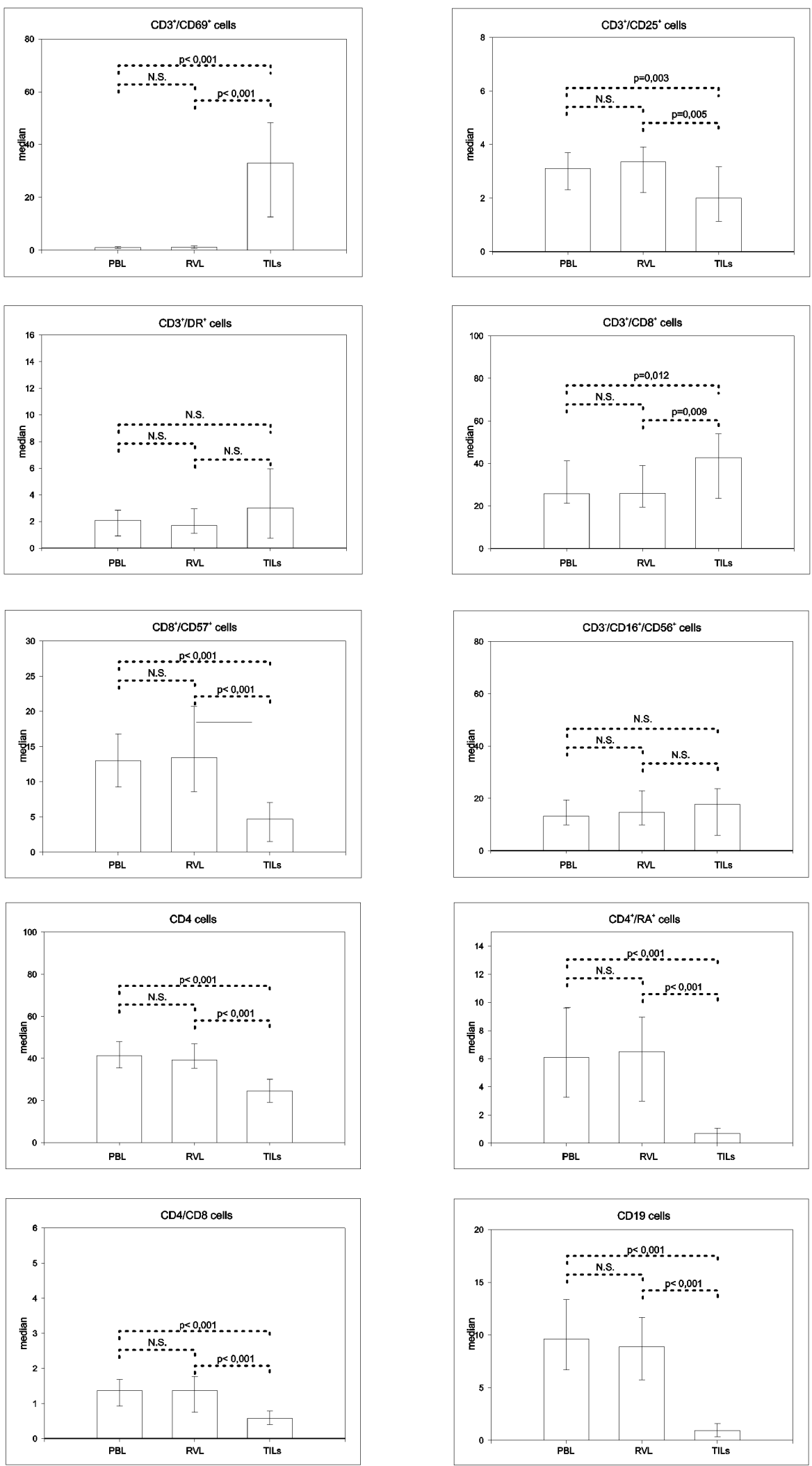

Fig. 1: Differencies in numbers of lymphocyte subpopulations in various compartments (peripheral blood lymphocytes PBL, renal vein lymphocytes -RVL, tumor-infiltrating lymphocytes -TILs) 
Tab. 1:

\begin{tabular}{|c|c|c|c|c|c|c|}
\hline & $\begin{array}{c}\text { Med. PBL } \\
25-75 \%\end{array}$ & $\begin{array}{c}\text { Med. RVL } \\
25-75 \%\end{array}$ & $\begin{array}{c}\text { Med. TILs } \\
25-75 \%\end{array}$ & $\begin{array}{c}\text { PBL-RVL } \\
\mathrm{p}\end{array}$ & $\begin{array}{c}\text { PBL - TILs } \\
\mathrm{p}\end{array}$ & $\begin{array}{c}\text { RVL - TILs } \\
\mathrm{p}\end{array}$ \\
\hline Suspensionpurity & $99.2(98.7-99.4)$ & $98.9(97.8-99.3)$ & $86.5(74.7-94.7)$ & 0.166 & $<0.001$ & $<0.001$ \\
\hline $\mathrm{CD}^{-} / 16^{+} 56^{+}$ & $13.2(9.9-19.4)$ & $14.8(9.9-22.9)$ & $17.7(5.9-23.8)$ & 0.362 & 0.528 & 1.000 \\
\hline $\mathrm{CD}^{+} / \mathrm{DR}^{+}$ & $2.1(0.9-2.9)$ & $1.7(1.1-2.9)$ & $3.0(0.8-5.9)$ & 0.872 & 0.211 & 0.204 \\
\hline $\mathrm{CD}^{+} / 69^{+}$ & $1.0(0.7-1.4)$ & $1.1(0.7-1.7)$ & $32.9(12.6-48.4)$ & 0.288 & $<0.001$ & $<0.001$ \\
\hline $\mathrm{CD}^{+}$ & $41.4(35.5-48.1)$ & $39.2(30.3-46.9)$ & $24.6(19.0-30.1)$ & 0.484 & $<0.001$ & $<0.001$ \\
\hline $\mathrm{CD}^{+}$ & $32.0(26.4-43.4)$ & $32.8(26.2-43.7)$ & $47.2(26.3-58.2)$ & 0.816 & 0.010 & 0.017 \\
\hline $\mathrm{CD}^{+}$ & $71.9(62.8-79.4)$ & $72.8(64.1-79.0)$ & $69.7(60.9-76.8)$ & 0.812 & 0.314 & 0.390 \\
\hline $\mathrm{CD}^{+} / \mathrm{CD}^{+}$ & $1.4(0.9-1.7)$ & $1.4(0.7-1.8)$ & $0.6(0.4-0.8)$ & 0.857 & $<0.001$ & $<0.001$ \\
\hline $\mathrm{CD}^{+} 9^{+}$ & $9.7(6.7-13.4)$ & $9.1(5.8-12.2)$ & $0.9(0.3-1.6)$ & 0.316 & $<0.001$ & $<0.001$ \\
\hline $\mathrm{CD}^{+} / 8^{+}$ & $25.8(21.3-41.2)$ & $26.1(19.5-38.9)$ & $42.6(23.5-53.9)$ & 0.975 & 0.009 & 0.012 \\
\hline $\mathrm{CD}^{-} / 8^{+}$ & $4.0(2.7-7.2)$ & $3.7(2.3-7.3)$ & $3.3(1.6-5.7)$ & 0.958 & 0.195 & 0.167 \\
\hline $\mathrm{CD}^{+} / 16^{+} 56^{+}$ & $5.5(2.2-9.7)$ & $5.6(3.0-9.4)$ & $2.9(1.6-5.4)$ & 0.766 & 0.018 & 0.004 \\
\hline $\mathrm{CD}^{+} / \mathrm{DR}^{+}$ & $1.1(0.5-2.4)$ & $1.2(0.6-1.5)$ & $1.6(0.5-5.1)$ & 0.619 & 0.282 & 0.114 \\
\hline $\mathrm{CD}^{+} 5^{+}$ & $3.3(2.7-4.1)$ & $3.6(2.5-4.6)$ & $2.6(1.4-4.7)$ & 0.495 & 0.102 & 0.071 \\
\hline $\mathrm{CD}^{+} / 25^{+}$ & $3.1(2.3-3.7)$ & $3.4(2.2-3.9)$ & $2.0(1.1-3.1)$ & 0.669 & 0.003 & 0.005 \\
\hline $\mathrm{CD}^{+} 7^{+}$ & $21.9(15.9-28.5)$ & $21.7(16.1-30.2)$ & $7.3(3.2-13.0)$ & 0.746 & $<0.001$ & $<0.001$ \\
\hline $\mathrm{CD}^{+} / 57^{+}$ & $13.0(9.3-16.8)$ & $13.5(8.6-20.7)$ & $4.7(1.5-7.1)$ & 0.613 & $<0.001$ & $<0.001$ \\
\hline $\mathrm{CD}^{+} / \mathrm{RA}^{+}$ & $6.1(3.3-9.6)$ & $6.5(3.0-8.9)$ & $0.7(0.0-1.1)$ & 0.980 & $<0.001$ & $<0.001$ \\
\hline $\mathrm{CD}^{+} / \mathrm{RO}^{+}$ & $25.5(22.8-35.9)$ & $23.9(22.5-32.2)$ & $22.2(14.6-29.1)$ & 0.376 & 0.123 & 0.212 \\
\hline $\mathrm{CD}^{+} / \alpha \beta^{+}$ & $24.7(20.8-37.7)$ & $26.7(19.4-41.9)$ & $37.4(19.9-52.6)$ & 0.880 & 0.065 & 0.107 \\
\hline
\end{tabular}

Abbreviations: PBL - peripheral blood lymphocytes; RVL - renal vein lymphocytes; TILs - tumour-infiltrating leukocytes; Med - median

Analysis of lymphocyte populations infiltrating renal cell carcinoma primary tumor compared with peripheral blood lymphocytes and renal vein lymphocytes.

$\mathrm{CD} 16^{+} / \mathrm{CD} 56^{+}$phenotype. $\mathrm{CD} 4^{+} \mathrm{T}$ lymphocytes and $\mathrm{B}$ lymphocytes are found by a majority of the authors as a minority population in TILs (26). In all the above-mentioned cellular populations isolated from RCC, the signs of early and late activation are detected as dendritic (5). For an effective anti-tumour response, tumour cells must be recognized by tumour-infiltrating monocytes and T lymphocytes. In this regard, the role of cells (DCs) is considered key. Dendritic cells present tumour antigens to cytotoxic lymphocytes and may prefer $\mathrm{CD} 4^{+}$subsets, and $\mathrm{Th} 1$ or Th2 response (2) with its cytokine spectrum (22).

In up to $70 \%$ of renal tumours, $\mathrm{CD}^{+} \mathrm{T}$ lymphocytes are the main cellular population of TIL cells (16). Our observations comply with this finding. The prevalence of $\mathrm{CD}^{+} \mathrm{CD}^{+}$cell population was also described in the stroma of other tumours $(7,15,23,32,33)$.

$\mathrm{CD} 4^{+} \mathrm{T}$ lymphocytes, which are the main producer of IL-2, show anti-tumour activity. The differentiation and activation of cytotoxic T lymphocytes and NK cells are induced by the effect of IL-2. The Th1 subset of CD $4^{+} \mathrm{T}$ lymphocytes produces IFN $\gamma$ and increases the cytotoxic function of $\mathrm{CD} 8^{+} \mathrm{T}$ lymphocytes. On the contrary, if the Th2 subset activity prevails, the antibody response is preferred through IL-4 and IL-5 and the function of Th1 subtype is inhibited. The presence of tumour-infiltrating effector cells and their activation are evidence of a local immune response (12).
Igarashi et al. compared the representation of lymphocytic subpopulations in TILs. Their study evaluated the correlation between the TIL phenotype and the response to interferon- $\alpha$ therapy. In patients with an advanced stage of disease (stages III and IV), in whom $\mathrm{CD}^{+} \mathrm{T}$ lymphocytes represented more than $40 \%$ of TIL cells, the partial remission or stabilization of the disease was achieved by the administration of interferon- $\alpha$. On the contrary, in patients with $\mathrm{CD}^{+}$TILs number higher than $25 \%$, no therapeutic response was achieved. The increase in $\mathrm{CD}^{+}$and decrease in $\mathrm{CD}^{+}$tumour-infiltrating lymphocytes were associated with a worse prognosis. Moreover, in vitro functional analyses of TILs confirmed that CD $4^{+} \mathrm{T}$ lymphocytes showed signs of activation, while $\mathrm{CD} 8^{+} \mathrm{T}$ lymphocytes, in some cases, did not express (exprime) the surface molecules, which was evidence of activation, and these cells were not able to induce effectively the cytolysis of target cells (14). On the contrary, in patients with localized disease, the phenotype of TILs does not have a prognostic significance $(28,30)$.

After presentation of the antigen, specific T lymphocytes are activated, which is associated with the change of expression of many molecules, for example HLA-DR molecule, the receptor for IL-2 (CD25) and the CD69 molecule $(17,24)$. The CD25 molecule reflects an early stage of cellular activation and is present in a higher number of tumour-infiltrating $\mathrm{T}$ lymphocytes compared to $\mathrm{T}$ lympho- 
cytes in peripheral blood (27). An increased expression of the CD25 molecule (an $\alpha$ chain of the receptor complex for IL-2) on $\mathrm{T}$ lymphocytes in renal cell carcinoma is considered to be evidence of local anti-tumour activity. An increased expression of this receptor is described in $\mathrm{CD}^{+}$ $\mathrm{T}$ lymphocytes after the specific and non-specific stimulation in vitro and in vivo conditions $(1,2,18,25)$. The expression of early activation molecule CD69 is detectable 2-3 hours after stimulation. Non-specific stimulation could have an effect on the expression of early marker activation during the separation of TILs from the tumour stroma, but the time of sample processing (the preparation of suspension up to the evaluation on the flow cytometer) did not exceed 60 minutes.

The expression of HLA-DR molecules is the manifestation of prolonged stimulation. Class II HLA-DR molecules may be seen in cells with a delay of 48-72 hours after antigen stimulation (6). The results of our study comply with other studies which describe the expression of HLA-DR molecules in CD3 and CD8 positive T lymphocytes (9, 29, 30). Although the representation of $\mathrm{CD}^{+} / \mathrm{DR}^{+}$and $\mathrm{CD} 8^{+} /$ $\mathrm{DR}^{+}$cells was higher in TILs than PBL in our patients, these differences were not significant

NK cells in peripheral blood are a phenotype-heterogeneous population. CD 56 molecule is present in nearly all NK cells, while CD 57 molecule is present only in mature NK cells. The presence of NK cells is important for the effectiveness of treatment with IL-2. Donskov et al. described the absence of $\mathrm{CD} 56^{+}$cells in tumours during the course of treatment of clear cell renal carcinoma (10). On the contrary, it was proven that the presence of CD57 positive cells is necessary for achieving the therapeutic response after the administration of IL-2. It was confirmed that the presence of $\mathrm{CD} 7^{+} \mathrm{NK}$ cells in the tumour has an influence on the survival of patients with renal, colorectal and stomach carcinomas. NK cells are considered to be the key population that checks tumour growth. The low number of NK cells among TILs is associated with a higher risk of tumour progression. The lack of $\mathrm{CD}^{-} \mathrm{CD} 56^{+} \mathrm{CD} 16^{+}$cells in peripheral blood and/or among TIL cells is associated with RCC patients at risk of metastasis development, which proves the protective role of these cells $(13,31)$. The representation of NK cells in peripheral blood and tumour stroma showed no difference in our patients.

The tumour infiltration by lymphocytes, which show cytotoxic activity targeted against tumour cells, is considered a sign of effective anti-tumour response. In spite of these findings, spontaneous tumoral regression and therapeutic response to biological treatment are seen in only a small amount of patients with renal carcinoma. The presence of activated $\mathrm{T}$ lymphocytes does not have to reflect the anti-tumour response. The increased expression of $C D$ 69 and HLA DR activation molecules and the low density of CD25 molecules on T lymphocytes are also seen in other diseases caused by or associated with immunopathological reactivity, for example in inflammatory diseases of con- nective tissue. It is probable that, in part of the patients, the tumour infiltration by activated lymphocytes is caused by cytokine and chemokine tumoural microenvironments. Stimulation by tumour antigens may be, in most cases, insufficient or completely missing. The growing tumour tissue is exposed to ischemia and undergoes necrosis if there is an insufficient vascular supply. The necrotic tissue is invaded by phagocytating cells that produce chemoatractants and pro-inflammatory cytokines. Endothelial cells of newly-created vessels produce a number of factors that also stimulate proliferation of $\mathrm{CD}^{+} \mathrm{T}$ lymphocytes. Th2 lymphocytes produce IL-13, which has a pro-angiogenic effect. Non-specific stimulation may be a consequence which is responsible for failure of immunological supervision (16, 29).

B lymphocytes are the minority population of TILs. Although the precise role of B lymphocytes is unknown, the expression of CD69 molecules in tumour-infiltrating B lymphocytes shows their participation in the anti-tumour response (19). In case of tumours, an antibody response to tumour antigens may lead to the blunting of epitopes recognized by specific cytotoxic $\mathrm{T}$ lymphocytes and thus making possible tumour growth. Higher representation of B lymphocytes among TILs was observed in patients with a predominance in $\mathrm{CD}^{+}$infiltrating lymphocyte and $\mathrm{Th} 2$ population activity, respectively (22).

The significance of the role of antigen-presenting cells was not unambiguously proven in tumour diseases in case of B lymphocytes $(3,21,26,32,33)$. In our patients, B lymphocytes were less than $1 \%$ of TILs and their numbers were significantly lower compared to their numbers in PBL.

Shabtai had a different opinion in his study that comparing representation of $\mathrm{T}$ and $\mathrm{B}$ lymphocytes in TILs and peripheral venous blood in 8 patients with advanced renal carcinoma. The ratio of the number of tumour-infiltrating B lymphocytes to B lymphocytes in peripheral blood was 2.4, while the ratio of tumour-infiltrating $\mathrm{T}$ lymphocytes to $\mathrm{T}$ lymphocytes in peripheral blood was 0.48 . Moreover, the $\mathrm{T}$ lymphocytic population was represented predominantly by $\mathrm{CD}^{+} / \mathrm{CD}^{+}$lymphocytes (27). In these patients $\mathrm{Th} 2$ response probably prevailed over Th1 response with production of antibodies blunting specific tumour antigens and cytokines, and consequently allowed the tumour growth (12).

\section{Conclusion}

We may sum up that immunocompetent cells are activated in renal cell carcinoma. However, transformation of these immunocompetent cells to effector cytotoxic T lymphocytes and NK cells is inhibited by so far unknown, but most probably multifactoral, mechanisms. It is not possible to exclude that in a majority of patients non-specific stimulation of TILs prevails. Th2 lymphocyte activation, characterized by the production of IL- 4 and IL-5, or regulating Tr (TH3) subset activity, producing TGF $\beta$ and IL-10, may be 
one of the causes of local cellular specific anti-tumour response failure. In this way, the desired protective activity of the Th1 subset (with production of IFN $\gamma$ ), which is important for cytotoxic activity against the tumour, is restricted. Due to the activity of Th2 lymphocytes, the predominant immune response is antibody production and the release of cytokines, for example IL-13 with its angiogenic activity, which may stimulate tumour growth. IL-10 inhibits the expansion of cytotoxic $\mathrm{CD}^{+} / \mathrm{CD}^{+} \mathrm{T}$ lymphocytes.

Cytokine tumoural environment, angiogenic factors and insufficient tumour antigenic stimuli are probably responsible for non-purposeful local inflammatory reactions and tumour progression. In most cases, intervention using interleukin- 2 and interferon $\alpha$ does not make it possible to break through the conditions under which tumour structures are tolerated.

\section{Acknowledgments}

This article came into existence thanks to grant No. NR/8914-4 provided for our research project by the Internal Grant Agency.

\section{References}

1. Bayer, A.L., Baliga, P., Woodward, J.E.: Differential effects of transferrin receptor blockade on cellular mechanisms involved in graft rejection. Transplant. Immunol., 1999:7:131.

2. Bayer, A.L., Baliga, P., Woodward, J.E.: Transferrin receptor in T cell activation and transplantation. J. Leukocyte Biol., 1998;64:19.

3. Bilik, R., Mor, C., Hazaz, B., Moroz, C.: Characterisation of T lymphocyte populations infiltrating primary breast cancer. Cancer Immunol. Immunother. 1989:28:143-7.

4. Böhm, M., Ittenson, A., Schierbaum, K.F., et al.: Pretreatment with interleukin-2 modulates peri-operative immuno-dysfunction in patients with renal cell carcinoma. Eur. Urol., 2002;41:458-68.

5. Bremers, A.J.A., Parmiani, G.: Immunology and immunotherapy of human cancer: present concepts and clinical developments. Crit. Rev. Oncol. Hematol., 2000;34:1-25

6. Chadburn, A., Inghirami, g., Knowels, D.M.: The kinetics and temporal expression of T cell activation-associated antigens CD15 (LeuM1), CD30 (Ki-1) EMA and CD11c (LeuM5) by benign activated T cells. Hematol. Pathol, 1992;6:193.

7. Chakraborty, N.G., Sporn, J.R., Pasquale, D.R., et al.: Suppression of lymphokine-activated killer cell generation by tumor-infiltrating lymphocytes. Clin. Immunol. Immunopathol., 1991:59:407-16.

8. Characiejus, D., Pašukoniené, V., Kazlauskaité, N., et al.: Predictive value of CD8highCD57+ lymphocyte subset in interferon therapy of patients with renal cell carcinoma. Anticancer Research, 2002;22:3679-84.

9. Coventry, B.J., Weeks, S.C., Heckford, S.E., et al.: Lack of IL-2 cytokine expression despite IL-2 messenger RNA transcription in tumor-infiltrating lymphocytes in primary human breast carcinoma: selective expression of early activation markers. J. Immunol., 1996;156:3486.

10. Donskov, F., Bennedsgaard, K.M., von der Maase, H., et al.: Intratumoural and peripheral blood lymphocyte subsets in patients with metastatic renal cell carcinoma undergoing interleukin-2 based immunotherapy: association to objective response and survival. Br. J. Cancer, 2002;87:194-201.

11. Elsässer-Beile, U., Gierschner, D., Welchner, T., Wetterauer, U.: Different expres- sion of Fas and Fas ligand in tumor infiltrating and perihperal lymphocytes of patients with renal cell carcinomas. Anticancer Research, 2003:23:433-8.

12. Elsässer-Beile, U., Grussenmeyer, T., Gierschner, D., et al.: Semiquantitative analysis of Th1 and Th2 cytokine expression in $\mathrm{CD}^{+}, \mathrm{CD}^{+}$, and $\mathrm{CD} 8^{+}$renal-cell-carcinoma-infiltrating lymphocytes. Cancer Immunol. Immunother., 1999;48:204-8.

13. Hayakawa, K., Morita, T., Augustus, L.B., et al.: Human renal cell carcinoma cells are able to activate natural killer cells. Int. J. Cancer, 1992;51:290.

14. Igarashi, T., Takahashi, H., Tobe, T., et al.: Effect of tumor-infiltrating lymphocyte subsets on prognosis and susceptibility to interferon therapy in patients with renal cell carcinoma. Urol. Int., 2002;69:51-56.

15. Koo, A.S., Tso, C.L., Shimabukuro, T., et al.: Autologous tumor-specific cytotoxicity of tumor-infiltrating lymphocytes derived from human renal cell carcinoma. J. Immunother., 1991;10:347-54.

16. Kowalczyk, D., Skorupski, W., Kwias, Z., Nowak, J.: Flow cytometric analysis of tumour-infiltrating lymphocytes in patients with renal cell carcinoma. Br. J. Urol., 1997;80:543-7.

17. Kronke, M., Leonard, W.J., Depper, J.M., Greene, W.C.: Sequential expression of genes involved in human T lymphocyte growth and differentiation. J. Exp. Med. $1985 ; 161: 1593-8$

18. Lucivero, G., Dalla Mora, L., Bresciano, E., et al.: Functional characteristics of cord blood T lymphocytes after lectin and anti-CD3 stimulation. Differences in the way $\mathrm{T}$ cells express activation molecules and proliferate. Int. J. Clin. Res., 1996;26:255.

19. Malinowski, K., Kono, K., Takayama, T., et al.: Inhibition of lymphocyte proliferative responses by renal cell carcinoma extract. Transplant. Proc., 1997;29:839.

20. Martel, C.L., Lara, P.N.: Renal cell carcinoma: current status and future directions. Crit. Rev. Oncol. Hematol., 2003;45:177-190.

21. Mitropoulos, D., Kooi, S., Rodriguez-Villanueva, J., Platsoucas, C.D.: Characterization of fresh (uncultured) tumour-infiltrating lymphocytes (TIL) and TIL-derivied $\mathrm{T}$ cell lines from patients with renal cell carcinoma. Clin. Exp. Immunol., 1994;97:321-7.

22. Netea, M.G., van der Meer, J.W.M., Sutmuller, R.P., et al.: From the Th1/Th2 paradigm towards a toll-like receptor/T-helper bias. Antimicrob. Agents Chemother., 2005;49(10):3991-6.

23. Panelli, M.C., Nagorsen, D., Wang, E., et al.: Mechanism of immune response during immunotherapy. Yonsei Med. J., 2004;45(Suppl.):15-17.

24. Reed, J.C., Alpers, J.D., Nowell, P.C., Hoover, R.G.: Sequential expression of protooncogenes during lecitin-stimulated mitogenesis of normal human lymphocytes. Proc. Natl. Acad. Sci. USA, 1986;83:3982-6.

25. Rodriguez, M.A., De Sanctis, J.B., Blasini, A.M., et al.: Human IFN-gamma upregulates IL-2 receptors in mitogen-activated T lymphocytes. Immunol., 1990; 69:554.

26. Santin, A.D., Ravaggi, A., Bellone, S., et al.: Tumor-infiltrating lymphocytes contain higher numbers of type 1 cytokine expressors and $\mathrm{DR}+\mathrm{T}$ cells compared with lymphocytes from tumor draining lymph nodes and peripheral blood in patients with cancer of the uterine cervix. Gynecol. Oncol., 2001;81:424-32.

27. Shabtai, M., Ye, H., Frischer, Z., et al.: Increased expression of activation markers in renal cell carcinoma infiltrating lymphocytes. J. Urol., 2002;168:2216-19.

28. Schoof, D.D., Terashima, Y., Peoples, G.E., et al.: CD4+ T cell clones isolated from human renal cell carcinoma possess the functional characteristics of Th2 helper cells. Cellular Immunol., 1993;150:114-23.

29. van den Hove, L.E., van Gool, S.W., van Poppel, H., et al.: Identification of an enriched CD4+ CD8alpha++ CD8beta+ T-cell subset among tumor-infiltrating lymphocytes in human renal cell carcinoma. Int. J. Cancer, 1997;71:178.

30. van den Hove, L.E., van Gool, S.W., van Poppel, H., et al.: Phenotype, cytokine production and cytolytic capacity of fresh (uncultured) tumour-infiltrating lymphocytes in human renal cell carcinoma. Clin. Exp. Immunol., 1997;109:501-9.

31. Whiteside, T.L., Herberman, R.B.: The role of natural killer cells in immune surveillance of cancer. Curr. Opinion Immunol., 1995;7:704-10.

32. Whitford, P., Mallon, E.A., George, W.D., Campbell, A.M.: Flow cytometric analysis of tumour infiltrating lymphocytes in breast cancer. Br. J. Cancer, 1990;62:971-5.

33. Zeromski, J., Dworacki, G., Kruk-Zagajewska, A., et al.: Assessment of immunophenotype of potentially cytotoxic tumor infiltrating cells in laryngeal carcinoma. Arch. Immunol. Ther. Exp., 1993;41:57-62

Submitted September 2006. Accepted July 2007.

\section{Corresponding author:}

Otakar Kopecký, M.D., University Hospital, 2nd Department of Internal Medicine, Division of Haematology, Sokolská 581, 50005 Hradec Králové, Czech Republic, e-mail: kopecky.otakar@nemocnicenachod.cz 